\title{
Hydrophilic polymer emboli: an under-recognized iatrogenic cause of ischemia and infarct
}

Rupal I Mehta ${ }^{1}$, Rashi I Mehta ${ }^{1}$, Orestes E Solis ${ }^{1}$, Reza Jahan ${ }^{2}$, Noriko Salamon ${ }^{3}$, Jonathan M Tobis ${ }^{4}$, William H Yong ${ }^{1}$, Harry V Vinters ${ }^{1,5}$ and Michael C Fishbein ${ }^{6}$

${ }^{1}$ Department of Pathology and Laboratory Medicine (Section of Neuropathology), University of California, Los Angeles, CA, USA; ${ }^{2}$ Department of Interventional Neuroradiology, University of California, Los Angeles, CA, USA; ${ }^{3}$ Department of Radiological Sciences, University of California, Los Angeles, CA, USA; ${ }^{4}$ Department of Medicine (Division of Cardiology), University of California, Los Angeles, CA, USA;

${ }^{5}$ Department of Neurology, The Mental Retardation Research Center, the Brain Research Institute, Los Angeles, CA, USA and ${ }^{6}$ Department of Pathology and Laboratory Medicine (Autopsy and Cardiopulmonary Pathology), University of California, Los Angeles, CA, USA

\begin{abstract}
With the increased use of percutaneous intravascular diagnostic and therapeutic devices, there is potential for embolization of materials introduced into the vasculature. We report nine cases of foreign body emboli in patients who underwent vascular procedures using hydrophilic-coated medical devices. The procedures performed included cardiac catheterization (four cases), diagnostic cerebral angiography (two cases), therapeutic cerebral angiography with coil embolization of intracerebral aneurysm (one case), lower extremity angiography (one case), and/or orthotopic cadaveric organ transplantation (three cases). Other procedures in these patients included hemodialysis and peripheral arterial or central venous catheterization. Clinical sequelae ranged from undetectable (no symptoms) to pulmonary infarction, stroke, ongoing gangrene, and/or death occurring within days to weeks of suspected embolization of foreign material. Microscopic findings in biopsy or autopsy tissue revealed aggregates of amorphous or lamellated, non-refractile, non-polarizable, predominantly basophilic foreign substances occluding intrapulmonary, intracerebral, or peripheral arteries. This is the largest series documenting embolization of polymer gel materials. Polymer gel is now widely used on several devices for interventional procedures worldwide, and we suspect that complications associated with iatrogenic embolization of this substance are under-recognized.

Modern Pathology (2010) 23, 921-930; doi:10.1038/modpathol.2010.74; published online 19 March 2010
\end{abstract}

Keywords: hydrophilic polymer; interventional procedure; catheter; guidewire; pulmonary infarct; cerebral infarct

Hydrophilic polymer coating is widely used on multiple medical devices and has made possible less invasive approaches to certain interventional procedures, thereby decreasing associated morbidity and mortality. Hydrophilic coating was initially used on Cook arterial introducer sheaths (Cook Medical, Bloomington, IN, USA) to decrease friction

Correspondence: Dr RI Mehta, MD, Department of Pathology and Laboratory Medicine (Section of Neuropathology), University of California, 10833 Le Conte Avenue, 18-126 CHS, Los Angeles, CA 90095, USA.

E-mail: RMehta@mednet.ucla.edu

Received 17 November 2009; revised and accepted 18 February 2010; published online 19 March 2010 between sheaths and vessel walls, thereby decreasing the frequency of arterial spasm and pain, and making possible the use of large sheaths in small arteries (namely the radial artery). This approach, that spares the femoral artery, has been shown to reduce complications relating to hemorrhage and delayed ambulation. ${ }^{1}$ Moreover, polymer-coated aneurysm coils have been shown to facilitate volumetric occlusion of aneurysms and induce early inflammation and thrombus organization, ${ }^{2,3}$ while using less total coil material, thereby mitigating some associated risks such as aneurysm rupture and coil migration.

Barnwell et al $(1997)^{4}$ described foreign bodies in intracranial vessels of four patients after use of an 
infusion microcatheter (the Fastracker-18 was subsequently discontinued). Since then, 'sterile inflammation' has been described as a rare complication of hydrophilic coating originating from medical devices. After cardiac catheterization and coronary angiography procedures, this has manifested clinically as painful, non-healing dermal wounds at the access site, ${ }^{5-10}$ shown on biopsy to be extravascular or perivascular granulomata harboring extracellular deposits of polymer material (likely originating from coated Cook arterial introducer sheaths). 'Aseptic' and 'chemical' meningitis, documented in five patients, ${ }^{11,12}$ likely resulted from disseminated polymer materials (although clinical findings in these cases were not confirmed by histopathologic evaluation). Intracerebral filament core has been shown in two patients with neurologic deficits after coil embolization procedures using Cerecyte (Micrus Endo-vascular, San Jose, CA, USA) ${ }^{9}$ and Matrix (Boston Scientific Neuro-vascular, Fremont, CA, USA $^{13}$ detachable coils. One of these cases, reported by our group, also involved widespread intracerebral embolization of hydrophilic polymer gel. ${ }^{13}$ Recently, hydrophilic polymer originating from a central venous catheter was found to embolize to the lung, resulting in cavitary lung nodules in a 34-year-old woman. ${ }^{14}$ Additional reports describe retained catheter fragments ${ }^{15,16}$ and embolized foreign materials ${ }^{17}$ after vascular intervention.

We have now identified several cases of intravascular foreign gel materials in surgical or autopsy pathology specimens. ${ }^{18}$ Retrospective review of clinical histories reveals that intravascular procedures had been performed in all patients. We herein describe the clinical course and histopathologic findings in nine patients who underwent multiple vascular interventions incorporating hydrophiliccoated medical devices, with foreign body emboli subsequently identified distant from the access site: five cases involve embolization to the pulmonary vasculature, three cases had polymer embolization within the brain, and one case had embolization to the foot. Several cases resulted in morbidity or directly contributed to the death of patients.

\section{Case summaries}

\section{Case 1}

An 87-year-old woman (earlier described ${ }^{13}$ ) with an unresectable supraclinoid carotid artery aneurysm presented with subarachnoid hemorrhage. She underwent coil embolization of the aneurysm using a combination of polymer-coated medical devices (see Table 1). The patient never fully regained consciousness after the procedure. Magnetic resonance imaging (MRI) and magnetic resonance angiography (MRA) on postoperative day 2 revealed scattered areas of acute infarct involving multiple bilateral vascular territories within the cerebral hemispheres, cerebellum, and pons. The brain at autopsy showed innumerable (diffuse) intravascular aggregates of amorphous foreign material, which was non-refractile, non-polarizable, granular, and predominantly basophilic. Rare vessels within the pons and cerebellum also contained lamellated eosinophilic foreign material (inset, Figure 3e). Vascular stenosis and obliteration were associated with discrete zonal areas of infarct (Figure 2c) and neointimal proliferation within the subcortical white matter, brainstem, and cerebellum. Scattered foci of foreign body reaction with giant cells were seen. Approximately 100 arteries (ranging from 13 to $400 \mu \mathrm{m}$ in diameter) were affected in 40 tissue sections of the brain sampled at autopsy.

\section{Case 2}

A 54-year-old man with a history of chronic atrial fibrillation underwent orthotopic heart transplantation for ischemic cardiomyopathy 2 years before death. He subsequently developed transplant coronary artery disease and reactivation of hepatitis B with cirrhosis, hepatorenal syndrome, and encephalopathy. In addition to several other vascular interventions, the patient underwent orthotopic liver transplantation 29 days before death (see Table 1). His postoperative course was complicated by fungal respiratory infection, septicemia, and renal failure, and he eventually developed a left pneumothorax and a fatal cardiac arrhythmia. At autopsy, aggregates of lamellated, non-refractile, non-polarizable, granular, basophilic foreign material were seen obstructing several small intrapulmonary arteries within both lungs. Ten affected arteries (ranging from 45 to $200 \mu \mathrm{m}$ in diameter) were found in seven routine pulmonary sections examined (Figure 1a). Foreign body reaction was noted within some affected vessels.

\section{Case 3}

A 71-year-old woman with a history of diabetes mellitus, hypertension, hyperlipidemia, hypothyroidism, and left breast carcinoma (status postleft mastectomy several years earlier) underwent right lung transplantation (and preoperative cardiac catheterization) for emphysema. Five years later, she presented with pneumonia. Work-up (including additional vascular manipulation, as per Table 1) revealed a solitary pulmonary nodule in the lingula. A biopsy of the mass revealed poorly differentiated carcinoma, and the patient underwent left lung transplantation. Intravascular lamellated, non-polarizable, non-refractile, granular, basophilic foreign material was incidentally discovered within small arteries of the explanted lung (in areas uninvolved by tumor) (Figure 1b). Twelve arteries (ranging from 25 to $900 \mu \mathrm{m}$ in diameter) were 
Table 1 Demographics of patients and interventional procedures performed (with device record)

\begin{tabular}{|c|c|c|c|c|c|c|}
\hline Case & Age/sex & $\begin{array}{l}\text { Comorbid } \\
\text { conditions }\end{array}$ & $\begin{array}{l}\text { Intravascular procedures and medical devices } \\
\text { utilized (where known) }\end{array}$ & $\begin{array}{l}\text { Location of } \\
\text { foreign body } \\
\text { emboli }\end{array}$ & Specimen & $\begin{array}{l}\text { Clinical } \\
\text { sequelae }\end{array}$ \\
\hline
\end{tabular}

Cerebral
aneurysm, HTN,
PVD, CAD

Coil embolization: 0.038 Terumo glidewire,

Echelon10 microcatheter, Matrix2 coil, Guglielmi coils, $6 \mathrm{~F}$ 80-cm shuttle sheath, 0.035 Cook Bentson guidewire, Simmons 2 catheter, 5 F VTK catheter, fasDasher 14 microguidewire

Central venous catheterization

Hemodialysis: 21 gauge seeker needle, dual-lumen temporary dialysis catheter

Heart Tx.

Cardiac catheterization (multiple): $8 \mathrm{~F}$ Cordis, (ischemic cardio- $7 \mathrm{~F}$ argon biopsy forceps, $7.5 \mathrm{~F}$ thermodilution, myopathy), 7F Swan-Ganz catheter, 7F sheath, $6 \mathrm{~F}$ sheath,

TCAD, HL, HTN, J-tipped guidewire, JL4 coronary catheter, JR4 AFib, liver Tx. (Hep B), DMII, Gout coronary catheter, $6 \mathrm{~F}$ pigtail catheter, $6 \mathrm{~F}$ Angio-Seal

Computed tomography angiography

Central venous catheterization

Peripherally inserted central catheterization:

$5 \mathrm{~F}$ non-valved double-lumen catheter, $5 \mathrm{~F}$

double-lumen arrow midline catheter

Transvenous pacemaker

Hemodialysis

Orthotopic liver Tx procedure: incorporated veno-venous bypass, intraoperative hemodialysis, intraoperative hepatic flushing

Transjugular liver biopsies

(emphysema),

Central venous catheterization: triple-lumen plastic catheter

DMII, HTN, HL, breast and lung CA, pneumonia

Computed tomography angiography

Peripherally inserted central catheterization:

$5 \mathrm{~F}$ peel-away sheath, 018 wire, polyurethane catheter, $5 \mathrm{~F}$ double-lumen arrow midline catheter, 5F non-valved double-lumen catheter Lung Tx procedure

Cardiac catheterization (*remote history) Liver

11.5 F 13-cm double-lumen dialysis catheter Arterial catheterization: 20 gauge sterile needle, guide wire, $16 \mathrm{~cm}$ soft 20 gauge catheter Orthotopic liver Tx procedure: incorporated double-lumen Hickman catheter, veno-venous bypass

Transjugular intrahepatic portosystemic shunt (with revision): $21 \mathrm{G}$ micropuncture needle, 018 wire, 0.035 Bentson wire, $5 \mathrm{~F}$ blue curved catheter, 9F Ring sheath, 035 Amplatz wire, Colapinto needle, 035-angled glidewire, 4F Teflon catheter, 9F short vascular sheath Computed tomography angiography
Cerebral angiography (4 vessel): $5 \mathrm{~F}$ Terumo-angled s/p gastric bypass, glide catheter, Terumo-angled guidewire, Bentson cerebral vasculitis wire, 6F Perclose

Peripherally inserted central catheterization

Polysubstance Cerebral angiography (4 vessel): Medi-Tech 8F abuse, HTN w/h/o sheath, 0.035 Cook, Bentson guidewire, 5F Vertintracranial bleed angled Glide catheter, $8 \mathrm{~F}$ concentric balloon guidecatheter, Terumo-angled guidewire, $6 \mathrm{~F}$ Perclose, 8F balloon guide-catheter, 18 L MERCI catheter, fasDasher 14 microguidewire Arterial catheterization: 4F Cook catheter Central venous catheterization

Sickle cell Ds w/ opioid dependence,
B/L cerebral Autopsy

cortex,

cerebellum,

brainstem,

leptomeninges

\begin{tabular}{|c|c|c|}
\hline $\begin{array}{l}\text { B/L lungs } \\
\text { (RUL, LUL, } \\
\text { LLL) }\end{array}$ & Autopsy & $\begin{array}{l}\text { Cardiac } \\
\text { arrhythmia, } \\
\text { death }\end{array}$ \\
\hline
\end{tabular}

$\begin{array}{lll}\text { Left lung } & \text { Surgical } & \text { None } \\ \text { (LLL) } & \text { biopsy (lung } & \end{array}$ wedge)

Left lung $\quad$ Autopsy $\quad$ Death
(LLL)

Right

occipital

cortex

Surgical

Stroke

biopsy

(stereotactic

brain biopsy)

Left

temporal

surgical

biopsy

(hematoma

Stroke w/ hemiparesis, aphasia
Stroke w/

hemiparesis death evacuation)
Left lung (LUL) Autopsy

Peripherally inserted central catheterization (multiple): $5 \mathrm{~F}$ peel-away sheath, polyurethane catheter, $5 \mathrm{~F}$ double-lumen arrow midline catheter
Pulmonary infarct, death 
Table 1 Continued

\begin{tabular}{|c|c|c|c|c|c|c|}
\hline Case & Age/sex & $\begin{array}{l}\text { Comorbid } \\
\text { conditions }\end{array}$ & $\begin{array}{l}\text { Intravascular procedures and medical devices } \\
\text { utilized (where known) }\end{array}$ & $\begin{array}{l}\text { Location of } \\
\text { foreign body } \\
\text { emboli }\end{array}$ & Specimen & $\begin{array}{l}\text { Clinical } \\
\text { sequelae }\end{array}$ \\
\hline & & $\begin{array}{l}\text { DMII, morbid } \\
\text { obesity, HTN }\end{array}$ & $\begin{array}{l}\text { Port-A-Cath } \\
\text { Central venous catheterization: 7F } 0.032 \text { Cook } \\
\text { catheter, triple-lumen and double-lumen plastic } \\
\text { catheters } \\
\text { Computed tomography angiography (chest) }\end{array}$ & & & \\
\hline 8 & $60 \mathrm{~F}$ & $\begin{array}{l}\text { B/L lung Tx. } \\
\text { (idiopathic } \\
\text { fibrosis), HTN, } \\
\text { HL pneumonia }\end{array}$ & $\begin{array}{l}\text { Cardiac catheterization } \\
\text { Central venous catheterization: triple-lumen } \\
\text { plastic catheter } \\
\text { Peripherally inserted central catheterization } \\
\text { (multiple): } 5 \mathrm{~F} \text { non-valved double-lumen catheter, } \\
5 \mathrm{~F} \text { double-lumen arrow midline catheter } \\
\text { Computed tomography angiography } \\
\text { Arterial catheterization: } 22 \text { gauge arterial } \\
\text { catheter } \\
\text { Hemodialysis }\end{array}$ & $\begin{array}{l}\text { Right lung } \\
\text { (RUL) }\end{array}$ & Autopsy & $\begin{array}{l}\text { Sepsis, } \\
\text { death }\end{array}$ \\
\hline 9 & $76 \mathrm{~F}$ & $\begin{array}{l}\text { CAD, PVD, HTN, } \\
\text { HL, CVA, ESRD } \\
\text { DMII, BRCA }\end{array}$ & $\begin{array}{l}\text { Selective catheterization and angiography of } \\
\text { bilateral lower extremity arteries: Bentson wire, } \\
6 \mathrm{~F} \text { sheath, angled glidewire, angled glide catheter, } \\
\text { stiff glidewire, } 6 \mathrm{~F} \text { Balkan sheath, } 0.035 \\
\text { Quick-Cross catheter, } 3 \times 120 \mathrm{~mm} \& 5 \times 60 \mathrm{~mm} \\
\text { angioplasty balloons, } 6 \times 120 \mathrm{~mm} \text { EV3 Protege } \\
\text { self-expanding stent, } 0.014 \text { Grand Slam wire, } 6 \mathrm{~F} \\
\text { Perclose } \\
\text { Laser Atherectomy (left leg arteries): } 1.7 \mathrm{~mm} \text { Turbo } \\
\text { laser catheter and 7F Turbo booster, Angio-Seal } \\
\text { Cardiac catheterization w/ thrombectomy, } \\
\text { angioplasty and stent of the RCA: } 5 \mathrm{~F} \text { sheath, } \\
\text { 5F JL4, 5F AL1, } 6 \mathrm{~F} \text { AL0.75 guide catheter with short } \\
\text { balance wire, Pronto device, } 2.5 \times 15 \text { mm Voyager } \\
\text { balloon, } 3.0 \times 15 \text { mm Xience stent, } 3.0 \times 15 \text { mm } \\
\text { PowerSail balloon } \\
\text { Peripheral catheterization and angiography } \\
\text { (pulse spray thrombolysis of L arm occluded AV } \\
\text { graft with Angiojet mechanical thrombectomy and } \\
\text { balloon angioplasty) } \\
\text { Cerebral angiography } \\
\text { Transvenous pacemaker-6F sheath, balloon tipped } \\
\text { pacer } \\
\text { Hemodialysis } \\
\text { Central venous catheterization: Hickman catheter } \\
\text { Peripherally inserted central catheterization } \\
\text { Computed tomography angiography (chest) }\end{array}$ & Left foot (heel) & $\begin{array}{l}\text { Surgical } \\
\text { biopsy } \\
\text { (debridement) }\end{array}$ & $\begin{array}{l}\text { Ongoing } \\
\text { gangrene }\end{array}$ \\
\hline
\end{tabular}

Afib, atrial fibrillation; B/L, bilateral; BRCA, breast carcinoma; CA, carcinoma; CAD, coronary artery disease; COD, cause of death; DM II, diabetes mellitus, Type 2; Ds, disease; F, French; Hep, hepatitis; HL, hyperlipidemia; HTN, hypertension; LLL, left lower lobe; LUL, left upper lobe; PVD, peripheral vascular disease; RUL, right upper lobe; TCAD, transplant coronary artery disease; Tx, transplant.

affected in seven routine tissue sections examined from the explanted lung.

\section{Case 4}

A 49-year-old man with end-stage liver disease secondary to hepatitis B with cirrhosis underwent allograft liver transplantation, complicated by recurrent peritoneal hemorrhage. The patient had several vascular interventions (see Table 1) and eventually developed line infection, septic shock, and multiple organ failure, progressing to death. Microscopic examination of the left lung at autopsy showed patchy areas of organizing pneumonia as well as intra-arterial aggregates of lamellated, nonrefractile, non-polarizable, granular, basophilic foreign material (Figure 1c). Two arteries (measuring 175 and $950 \mu \mathrm{m}$ in diameter) were affected in five routine pulmonary sections examined. Foreign body reaction was occasionally noted; a few additional vessels showed fibrous occlusion.

\section{Case 5}

A 36-year-old woman with a history of gastric bypass (performed 2 years before admission) 



Figure 1 Photomicrographs showing intravascular foreign material in cases 2-9. Embolized foreign material was seen within the (a) right lung, upper lobe (case 2); (b) left lung, lingula (case 3); (c) left lung, lower lobe (case 4); (d) right occipital cortex (case 5); (e) left temporal cortex (case 6); (f) left lung, upper lobe (case 7); (g) right lung, upper lobe (case 8); and (h) left foot (case 9). (a-h) Hematoxylin and eosin $(\mathrm{H} \& \mathrm{E})(\times 600$ at original magnification). 
presented with altered mental status, behavioral and postural changes, and decreased respiration. MRI of the brain revealed T2/FLAIR hyperintensities involving the deep and subcortical white matter, left cerebral peduncle, and middle cerebellar peduncles. The clinico-radiological findings were suggestive of a demyelinating process. Four-vessel cerebral angiogram (see Table 1) showed no evidence of vasculitis. Stereotactic biopsy of the right occipital cortex performed 13 days after angiography showed intravascular aggregates of lamellated, non-polarizable, non-refractile colorless foreign material with arterial occlusion (Figure 1d), and intravascular foreign body reaction, recognized even at the time of frozen section. Two arteries (measuring 188 and $600 \mu \mathrm{m}$ in diameter) were affected in three tissue sections examined. One vessel showed linear stenosis and/or occlusion along a longitudinal course of $4 \mathrm{~mm}$. Fibrinoid necrosis, microthrombus formation, and luminal fibrosis with focal recanalization were identified. Neuronal hypoxic ischemic changes and nodular areas of neovascularization were also noted adjacent to the occluded vessels (Figure 2e).

\section{Case 6}

A 54-year-old man with a history of hypertension and active polysubstance abuse (including tobacco, alcohol, marijuana, and cocaine) developed sudden aphasia and right hemiplegia. He was found to have an occlusion in the left middle cerebral artery, M2 segment, on computed tomography angiogram. A mechanical embolus removal in cerebral ischemia procedure was initially undertaken (see Table 1 for summary of vascular interventions). However, during the procedure, the patient spontaneously recanalized his left M2 segment, making the procedure unnecessary, although repeat imaging studies showed multiple small emboli within distal branches of the left anterior and middle cerebral arteries. Subsequent non-contrast head CT and MRI of the brain with and without contrast showed infarction involving the left middle and posterior cerebral artery territories. MRA performed subsequent to the catheter angiogram showed attenuation of the distal left middle cerebral arterial branches, without occlusion of the M1 or M2 segments. Parenchymal hematoma evacuation was performed 3 days after the angiogram. Histologic examination of fragments of neuroglial tissue received with the hematoma specimen revealed lamellated, non-refractile, non-polarizable, granular, basophilic foreign intravascular material (Figure 1e) with adjacent histiocytic aggregates. Six arterioles (ranging from 50 to $88 \mu \mathrm{m}$ in diameter) were affected in three tissue sections examined. Microthrombus formation and white matter astrogliosis were noted in addition to neuronal hypoxic ischemic changes.

\section{Case 7}

A hypertensive 22-year-old woman with long-standing sickle cell disease had multiple associated sequelae (including frequent pain crises and lower extremity deep venous thrombosis). Her disease and comorbidities (including urinary tract infections and cellulitis) required numerous intravenous lines for administration of antibiotics and pain medications (see Table 1). The patient developed shortness of breath 6 weeks before death. Imaging studies performed 5 days before death showed changes consistent with pneumonia. Four days before death, she developed severe hypotension and progressive shortness of breath requiring intubation. Repeated work-up was negative for pulmonary embolism. The patient was later found unresponsive. At autopsy, the lungs were heavy with peripheral infarcts in the right $(3.7 \mathrm{~cm}$, wedge shaped) and left $(3.3 \mathrm{~cm}$, ovoid nodule) upper lobes. No definite pulmonary emboli were identified. However, microscopic sections revealed bilateral, old, and recent microthrombi in the pulmonary arterial vasculature (multifocal, in a patternless distribution, occasionally with recanalization; Figures 2a and b). Lamellated, non-refractile, non-polarizable, granular, basophilic foreign material (Figure 1f) was seen obstructing intraparenchymal arteries. The affected vessels showed focal foreign body reaction and involved the grossly visible leftsided necrotic pulmonary nodule (Figure 2f). Six arteries (ranging from 88 to $850 \mu \mathrm{m}$ in diameter) were affected in 12 routine pulmonary sections sampled at autopsy.

\section{Case 8}

A 60-year-old woman with hypertension and hyperlipidemia underwent bilateral lung transplantation and preoperative cardiac catheterization for idiopathic pulmonary fibrosis 16 months before death. Her postoperative course was complicated by allograft rejection and polymicrobial pneumonia necessitating multiple hospital admissions (Table 1). She ultimately developed septic shock and cardiorespiratory failure progressing to death. Autopsy revealed bronchiolitis obliterans and diffuse alveolar damage. Also noted within intraparenchymal arteries of the right lung were aggregates of lamellated, nonpolarizable, non-refractile, granular, basophilic foreign material (Figure 1g). Three arteries (ranging from $113 \mu \mathrm{m}$ to $1 \mathrm{~mm}$ in diameter) were affected in 12 pulmonary tissue sections examined at autopsy. One vessel showed linear stenosis and/or occlusion along a longitudinal course of $2 \mathrm{~mm}$, whereas another showed near-total fibrous occlusion.

\section{Case 9}

A 76-year-old woman presented with a history of diabetes mellitus, coronary artery disease, hypertension, 


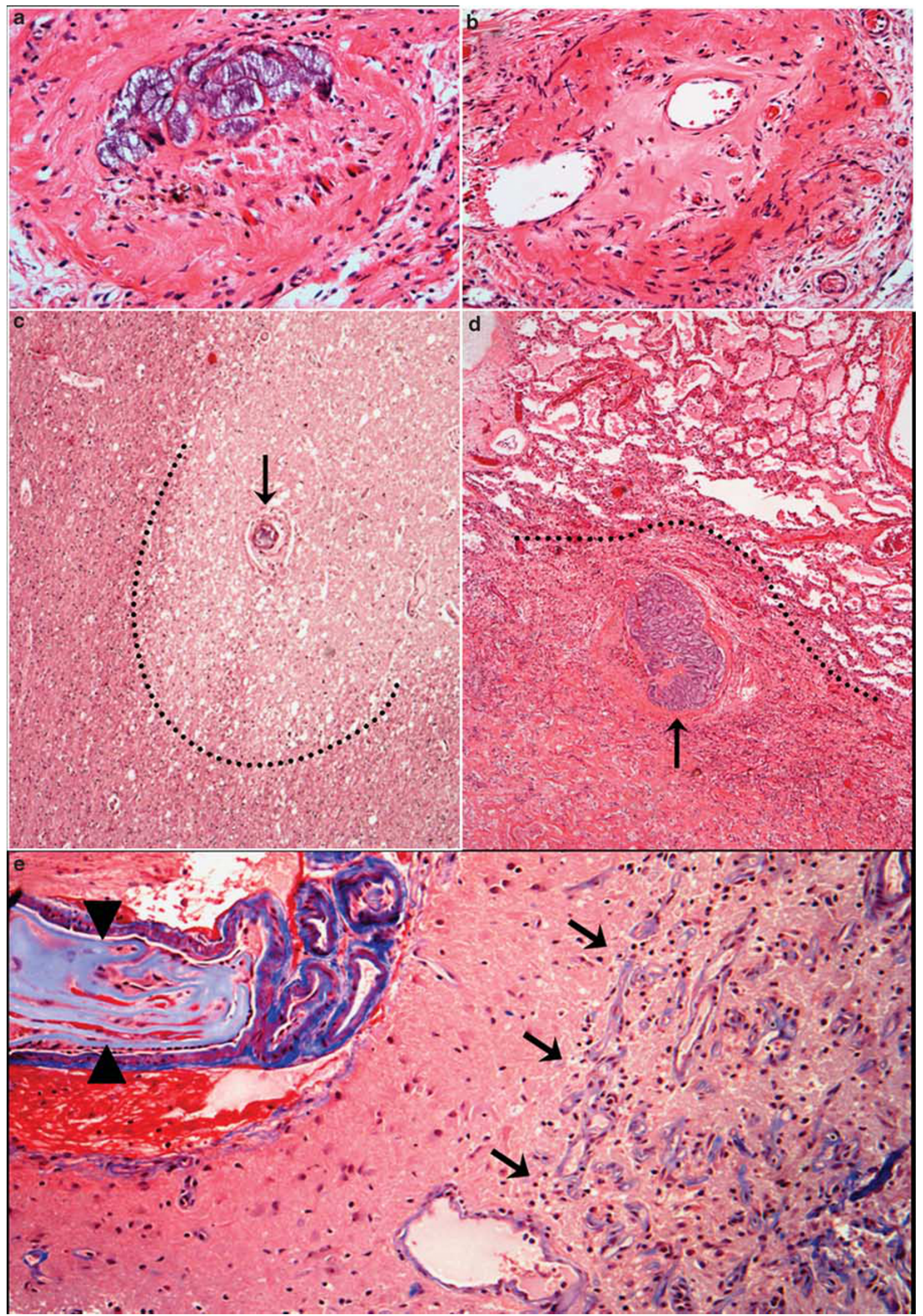

Figure 2 Different tissue reactions to foreign material emboli. Microthrombus formation was noted in case 5 (a), with evidence of recanalization (b). Zones of infarcts (dotted lines) were seen adjacent to occluded arteries within the brain (c, case 1) and the lung (d, case 7). (e) Granulation tissue, probably healing cerebral infarction (arrows), was identified adjacent to occlusive foreign material in the brain (arrowheads). (a-d) Hematoxylin and eosin (H\&E). (e) Masson's trichrome stain. (a, b) $\times 600$ at original magnification; (c-e) $\times 40$ at original magnification. 
stroke, end-stage renal disease (on hemodialysis), and peripheral vascular disease with non-healing ulcers of the lower extremities. She underwent a wide variety of interventional procedures during her medical course (Table 1), including bilateral lower extremity angiography with laser atherectomy and balloon angioplasty, arterio-venous fistula revision, and therapeutic cardiac catheterization (including thrombectomy and stenting of the right coronary artery). Eventual biopsy of a non-purulent, non-healing left heel lesion revealed gangrenous soft tissue with an intravascular focus of lamellated, non-polarizable, non-refractile, granular, basophilic foreign material (Figure 1h). The involved vessel measured $85 \mu \mathrm{m}$ diameter and exhibited adjacent foreign body type reaction.

\section{Microscopic examination of medical devices ex vivo}

To attempt to determine the source of the foreign material emboli, we examined the histologic appearance of several different devices ex vivo and compared the histology with that of the material we observed in the patients' specimens. Matrix2 embolization coils (Boston Scientific Neurovascular, Fremont, CA, USA) and Terumo Glidewires (Terumo Medical, Somerset, NJ, USA) were flushed with phosphate-buffered saline. Segments of the device tips were stretched by pulling opposite ends apart with forceps. The segments were then stained with hematoxylin and eosin (H\&E), mounted on glass slides, and coverslipped. A steel blade was used to scrape off coating from other segments of the devices, which yielded long strips of gel that were submitted for routine tissue processing (ie the material was formalin fixed, paraffin embedded, sectioned, mounted on a glass slide, stained with H\&E, and coverslipped). The procedure was repeated on hydrated, intact segments of Echelon 10 microcatheter as well as several other coated and non-coated vascular devices listed on Table 1. Microscopic examination of only polymer-coated devices showed non-polarizable, non-refractile, often granular coating material (either basophilic, eosinophilic, colorless, or gray-black in color). Representative coated medical devices are shown in Figure 3.

\section{Discussion}

Hydrophilic polymers of various composition are now widely used on common catheters and interventional medical devices in which they serve a lubricating function, while also imparting biocompatible surfaces that minimize biofilm formation. ${ }^{19}$ Emerging drug-binding, second generation polymers (ie bioactive polymers) deliver bound drugs to targeted, intravascular sites. For instance, hydrophilic polymers with antimicrobial capabilities are currently used on central venous catheter kits in hopes of decreasing morbidity and mortality associated with line infections and sepsis. ${ }^{20,21}$ Drug eluting cardiac stents incorporating polymer substances are routinely used during cardiac revascularization procedures. Expanding nanotechnology pertaining to polymer chemistry may soon assist in chemotherapy administration, eg for use on coated peripherally inserted central catheters. This evolving technology may be desirable as a mechanism of achieving controlled localized drug delivery, while limiting systemic drug toxicity and improving effectiveness and compliance.

Nevertheless, the findings in four cases described here strongly suggest that aggregates of embolized polymer initially obstructed large vessels either within the brain, lung, or lower extremity, resulting in clinical and/or radiologic evidence of ischemia within defined large arterial territories. Correlation with pathologic findings suggests that the polymer aggregates subsequently underwent partial dissolution, fragmentation, and further embolization to reach smaller caliber vessels in which they occluded small blood vessels (in 100\% of cases) and induced histiocyte infiltration and foreign body reaction (in $78 \%$ of cases). In this manner, a single aggregate of stripped polymer may act as a migrating embolic source, inducing unstable zones of ischemia and/or infarct as the polymer aggregate gradually dissolves. Indeed, in two of our fatal cases (ie cases 1 and 7), relatively large territorial cerebral or pulmonary infarcts occurred (see Figures 2c and d).

The cases described here were all identified prospectively at a single institution over a relatively brief period of time, just 2 years. Although the frequency of this phenomenon of polymer gel embolization is unknown, identification of these cases indicates that it is not a rare phenomenon. The patients described here were all extremely ill and underwent several vascular interventions using various coated medical devices. Therefore, the causative device(s) cannot definitively be identified in many cases. Moreover, even in fatal cases, the histopathologic findings are extremely subtle, involving unpredictable and scattered small vascular channels, which may not be readily identified on initial histologic examination. Notably, the vessels affected were all $<1 \mathrm{~mm}$ (and predominantly $15-200 \mu \mathrm{m}$ in diameter); these dimensions are below the spatial resolution of conventional imaging modalities.

Polymer-coated interventional devices and catheters are now frequently used worldwide. As biomedical applications for hydrophilic polymer gradually expand, we suspect that adverse effects associated with their use will become more apparent. Although embolic events after vascular intervention are usually clinically attributed to atheroemboli and/or thromboemboli, iatrogenic embolization of hydrophilic polymer should be considered in the clinical differential. In suspected 


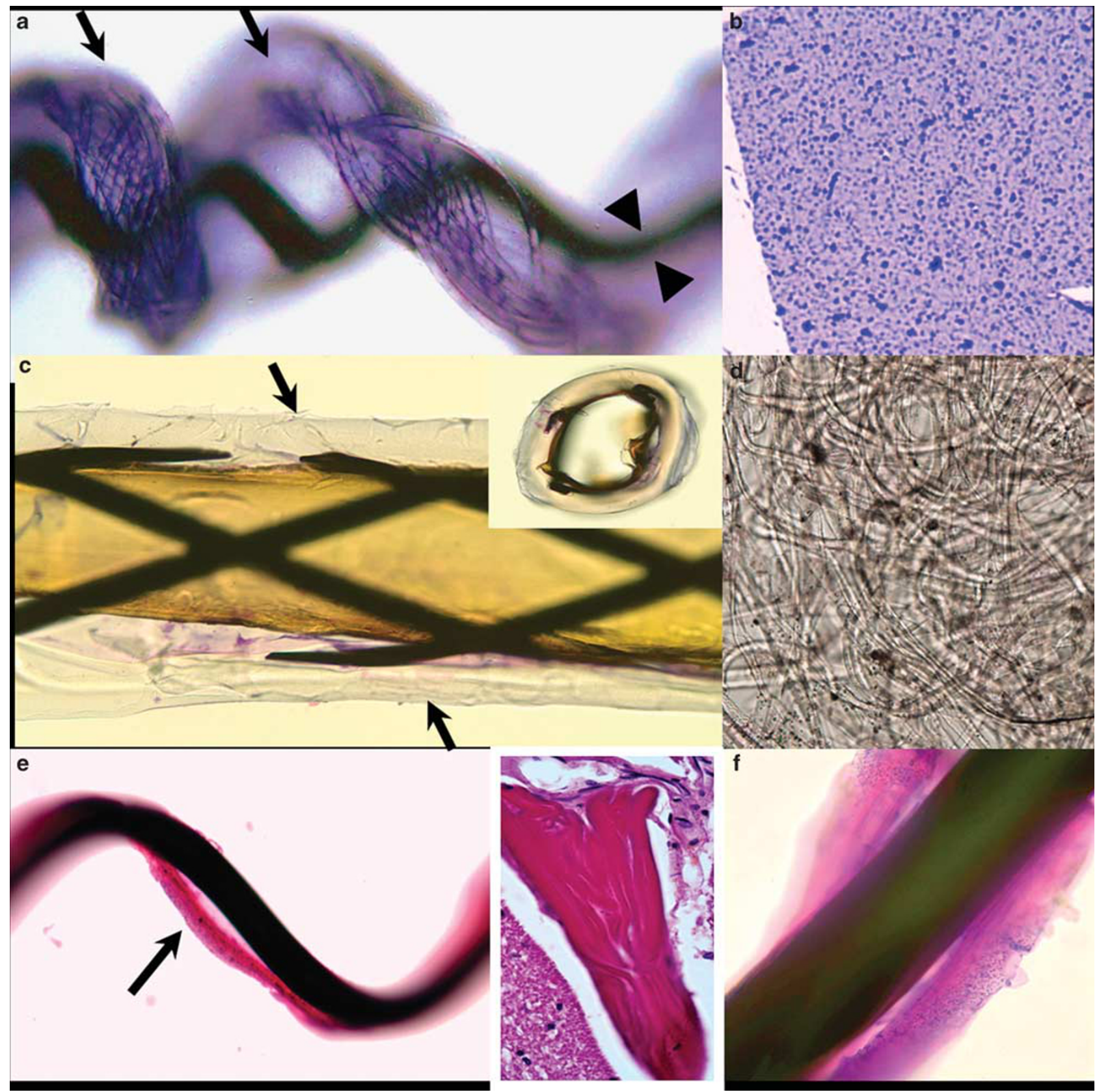

Figure 3 Ex vivo appearances of hydrophilic polymer. Light microscopic appearances of hydrophilic polymer coating on ex vivo medical devices were morphologically indistinguishable from foreign material seen in vivo in patients' small vessels on pathologic evaluation. (a) Hydrophilic coating on matrix coil (arrows) is visualized as weaved filaments of gel wrapped around the platinum core (arrowheads) $(\times 400)$, and (b) as basophilic granular non-refractile material on smear preparation $(\times 1000)$. (c) Echelon 10 microcatheter displays colorless polymer coat (arrows) $(\times 400)$, which $(\mathbf{d})$ formed a long, convoluted, gelatinous strip on scrape smear preparation $(\times 600)$. $(\mathbf{e}, \mathbf{f})$ Terumo Glidewire displays an eosinophilic polymer coat (arrow) $(\mathbf{e}, \times 400 ; \mathbf{f}, \times 600)$ identical to occlusive intravascular foreign material found in case 1 (inset). (a-f) Hematoxylin and eosin (H\&E).

cases, surgical biopsy may be helpful. Although polymer materials eventually biodegrade in vivo, the time course varies with polymer composition from several weeks to several months, allowing plenty of time during which permanent sequelae may develop. Thus, patients should be carefully monitored as embolism occurred to the pulmonary, cerebral, or peripheral arterial circulations in those described here and directly contributed to death in at least two cases.

\section{Acknowledgements}

This work is supported by the Translational Research Fund (TRF) sponsored by the Department of Pathology and Laboratory Medicine at UCLA (RIM, RIM, and HVV) as well as the Oppenheimer Program Clinical Translational Seed Grant (RIM, WHY, HVV). HVV is supported, in part, by the Daljit $S$ and Elaine Sarkaria Chair in Diagnostic Medicine. HVV and WHY are supported, in part, by UCLA SPOTRIAS 
grant NS044378. This work was presented in part at the 85th Annual Meeting of the American Association of Neuropathologists (11-14 June 2009 San Antonio, TX, USA).

\section{Disclosure/conflict of interest}

The authors declare no conflict of interest.

\section{References}

1 Mann T, Cubeddu G, Bowen J, et al. Stenting in acute coronary syndromes: a comparison of radial versus femoral access sites. J Am Coll Cardiol 1998;32:572-576.

2 Murayama Y, Tateshima S, Gonzalez NR, et al. Matrix and bioabsorbable polymeric coils accelerate healing of intracranial aneurysms: long-term experimental study. Stroke 2003;34:2031-2037.

3 Gaba RC, Ansari SA, Roy SS, et al. Embolization of intracranial aneurysms with hydrogel-coated coils versus inert platinum coils: effects on packing density, coil length and quantity, procedure performance, cost, length of hospital stay, and durability of therapy. Stroke 2006;37:1443-1450.

4 Barnwell SL, D’Agostino AN, Shapiro SL, et al. Foreign bodies in small arteries after use of an infusion microcatheter. Am J Neuroradiol 1997;18:1886-1889.

5 Subramanian R, White CJ, Sternbergh III WC, et al. Nonhealing wound resulting from a foreign-body reaction to a radial arterial sheath. Cathet Cardiovasc Intervent 2003;59:205-206.

6 Kozak M, Adams DR, Ioffreda MD, et al. Sterile inflammation associated with transradial catheterization and hydrophilic sheaths. Cathet Cardiovasc Intervent 2003;59:207-213.

7 Ziakas A, Karkavelas G, Mochlas S. Sterile inflammation after transradial catheterization using a hydrophilic sheath: a case report. Int J Cardiol 2005;99:495-496.

8 Tharmaratnam D, Webber S, Owens P. Sterile abscess formation as a complication of hydrophilic radial artery cannulation. Int J Cardiol 2008;130:e52.

9 Fealey ME, Edwards WD, Giannini C, et al. Complications of endovascular polymers associated with vascular introducer sheaths and metallic coils in 3 patients, with literature review. Am J Surg Pathol 2008;32:1310-1316.
10 Tharmaratnam D, Webber S, Owens P. Adverse local reactions to the use of hydrophilic sheaths for radial artery canulation. Int J Cardiol 2008. [Epub ahead of print].

$11 \mathrm{Im} \mathrm{SH}$, Han MH, Kwon BJ, et al. Aseptic meningitis after embolization of cerebral aneurysms using hydrogel-coated coils: report of three cases. Am J Neuroradiol 2007;28:511-512.

12 Meyers PM, Lavine SD, Fitzsimmons BR, et al. Chemical meningitis after cerebral aneurysm treatment using two second-generation aneurysm coils: report of two cases. Neurosurgery 2004;55:1222.

13 Mehta RI, Mehta RI, Fishbein MC, et al. Intravascular polymer material following coil embolization of a giant cerebral aneurysm. Hum Pathol 2009;40:1803-1807.

14 Allan RW, Alnuaimat H, Edwards WD, et al. Embolization of hydrophilic catheter coating to the lungs: report of a case mimicking granulomatous vasculitis. Am J Clin Pathol 2009;132:794-797.

15 Milbrandta K, Beaudrya $\mathrm{P}$, Andersonb R, et al. A multiinstitutional review of central venous line complications: retained intravascular fragments. J Pediatr Surg 2009;44:972-976.

16 Prewitt KC, Resar JR, Brinker JA. Fragmentation and embolization of a plastic-coated guidewire. Cathet Cardiovasc Diagn 1993;30:27-29.

17 Lechpammer M, Marshall A, Juraszek A, et al. Embolic foreign material in the central nervous system of children dying with heart disease and a history of instrumentation (abstract). J Neuropathol Exp Neurol 2009;68:578.

18 Mehta RI, Mehta RI, Fishbein MC, et al. Intravascular polymer material following interventional procedures (abstract). J Neuropathol Exp Neurol 2009;68:578.

19 Tamilvanan S, Venkateshan N, Ludwig A. The potential of lipid- and polymer-based drug delivery carriers for eradicating biofilm consortia on device-related nosocomial infections. J Control Release 2008;128: $2-22$.

20 Darouiche RO, Raad II, Heard SO, Catheter Study Group, et al. A comparison of two antimicrobialimpregnated central venous catheters. N Engl J Med 1999;340:1-8

21 Raad I, Darouiche R, Dupuis J, et al. Central venous catheters coated with minocycline and rifampin for the prevention of catheter-related colonization and bloodstream infections. Ann Intern Med 1997;127: 267-274. 